\title{
Validated Hptlc Method for Simultaneous Determination of Ceftriaxone Sodium and Tazobactam Sodium in Combined Dosage Form
}

\author{
Mr. Sanjay S. Malgundkar ${ }^{1}$, Dr. Saira Mulla ${ }^{2} *$ \\ ${ }^{1,2}$ Shri Jjt University, Vidyanagari, Churu-Jhunjhunu Road, Chudela, District-Jhunjhunu, Rajasthan-333001
}

\begin{abstract}
This paper describes a new simple, accurate and precise HPTLC method for simultaneous estimation Ceftriaxone sodium and Tazobactam sodium as bulk and dry powder for injection in combined dosages form. In this method, the densitograms were developed using mobile phase of 1-propanol: Methanol: Diethyl amine: Water (14:2:1:2.5 v/v). Aluminum plate coated with the silica Gel $60 F_{254}$ was used as stationary phase. Densitometric evaluation of the separated bands was performed at $288 \mathrm{~nm}$. The Rf values of Ceftriaxone sodium and Tazobactam sodium are $0.50 \pm 0.01$ and $0.67 \pm 0.01$ respectively.

The method was linear over the concentration range of $100 \mathrm{ng}$ to $200 \mathrm{ng} / \mathrm{spot}$ and $160 \mathrm{ng}$ to $360 \mathrm{ng} / \mathrm{spot}$ of Ceftriaxone sodium and Tazobactam sodium respectively. Precision of the method was evaluated by calculating $R S D$ for peak response by inerday and intraday analysis. The results were Ceftriaxone sodium: Inter day RSD of peak response $1.46 \%$ Intraday RSD $1.45 \%$ and for Tazobactam sodium Interday RSD of peak response $1.38 \%$ and Intraday RSD 2.0 . Accuracy was determined in terms of percentage recovery at three concentration levels for Ceftriaxone sodium $=R S D \quad 92.36 \%, \quad 91.59 \%$ and $91.77 \%$ and for Tazobactam sodium $=$ 93.96\% , 93.37\% and $93.25 \%$ respectively. Specificity was proved by spectral analysis of Cetfriaxone sodium and Tazobactam sodium and overlaying the standard spectra and sample spectra respectively.There was no any interference of mobile phase and diluents at the Rf values of Ceftriaxone sodium and Tazobactam sodium . Validation was done in accordance with the ICH Guidelines.
\end{abstract}

Key words: High performance thin layer chromatography, microgram, nano gram, Ceftriaxone sodium and Tazobactam sodium .

\section{Introduction}

Ceftriaxone sodium is chemically Disodium $(6 R, 7 R)-7$ - [[(2Z)- (2-aminothiazol- 4-yl)(methoxyimino) acetyl]amino]-3-[[(2- methy 1-6-oxido-5-oxo-2, 5-dihydro-1,2,4-triazin-3-yl)sulphanyl] methyl] -8-oxo-5-thia-1azabicyclo [4.2.0] oct-2-ene-2- carboxylate 3.5 hydrate. It is Semi-synthetic product derived from a fermentation product. Molecular formula of Ceftriaxone sodium is $\mathrm{C}_{18} \mathrm{H}_{16} \mathrm{~N}_{8} \mathrm{Na}_{2} \mathrm{O}_{7} \mathrm{~S}_{3}, 3 \frac{1}{2} \mathrm{H}_{2} \mathrm{O}$. Molecular mass of Ceftriaxone sodium is 662.0 and CAS number is 104376-79-6.

Ceftriaxone sodium is a third-generation cephalosporin antibiotic. Like other third-generation cephalosporins, it has broad-spectrum activity against Gram-positive and Gram-negative bacteria. In most cases, it is considered to be equivalent to cefotaxime in terms of safety and efficacy.

Ceftriaxone sodium is often used (in combination, but not direct, with macrolide and/ or aminoglycoside antibiotics) for the treatment of community-acquired or mild to moderate health careassociated pneumonia. It is also a choice drug for treatment of bacterial meningitis. In pediatrics; it is commonly used in febrile infants between 4 and 8 weeks of age who are admitted to the hospital to exclude sepsis. It has also been used in the treatment of Lyme disease, typhoid fever, and gonorrhea. Ceftriaxone sodium is freely soluble in water, sparingly soluble in methanol, very slightly soluble in anhydrous ethanol.

Tazobactam sodium is chemically (2S,3S,5R)-3-methyl-7-oxo-3-(1H-1,2,3-triazol-1-ylmethyl)-4-thia1-azabicyclo[3.2.0]heptane-2-carboxylic acid 4,4-dioxide. Molecular formula of Tazobactam is $\mathrm{C}_{10} \mathrm{H}_{12} \mathrm{~N}_{4} \mathrm{O}_{5} \mathrm{~S}$ and CAS Number is $89786-04-9$. Molecular mass of the Tazobactam is $300.289 \mathrm{~g} / \mathrm{mol}$

Tazobactam is a compound that inhibits the action of bacterial $\beta$-lactamases. It is combined with the extended spectrum $\beta$-lactam antibiotic piperacillin in the drug piperacillin / tazobactam (trade name Tazocin; also Zosyn, Piprataz). It is one of the preferred antibiotic treatments for nosocomial pneumonia caused by Pseudomonas aeruginosa. It broadens the spectrum of piperacillin by making it effective against organisms that express $\beta$ lactamase and would normally degrade piperacillin. Tazobactam sodium is a derivative of the penicillin nucleus and is a penicillanic acid sulfone

Literature survey reveals that the several analytical methods have been reported for estimation of Ceftriaxone sodium and Tazobactam sodium as an individual drug substance and in the combination drug by High performance liquid chromatography and UV-VIS spectrophotometric method. 
A simple, accurate and precise HPTLC method for simultaneous estimation Ceftriaxone sodium and Tazobactam sodium in dry powder injection manufactured in the combined dosages form has been developed.<smiles>CO/N=C(/C(=O)N[C@H]1C(=O)N2C(C(N)=O)=C(CSc3nc(=O)c(OC)nn3C)CS[C@H]12)c1csc(N)n1</smiles>

(a)

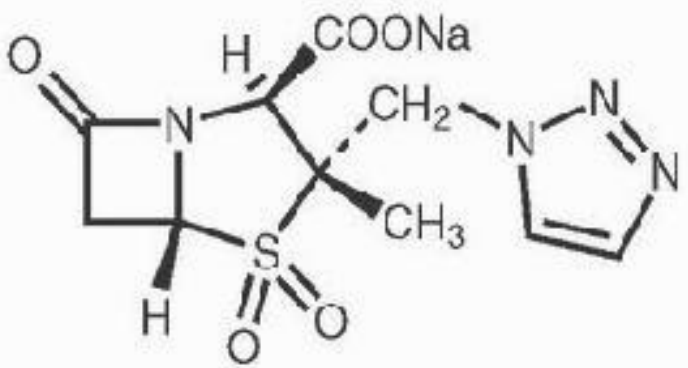

(b)

Figure 1. Structure of Ceftriaxone sodium (a) and Structure of Tazobactam sodium (b)

\subsection{Chemicals and Reagents}

\section{Materials and Methods}

Working Standard of Ceftriaxone sodium and Tazobactam sodium were provided by Aurobindo Pharma Ltd through Mr. Vikrant Tamse-Senior Manager Purchase as Gererous Gift samples for development study. Ceftriaxone sodium and Tazobactam sodium manufactured by Alpic Biotech with a brand Name of Aacef-T were procured from market for study. All other reagents used were analytical grade and were procured from Merck chemicals Mumbai, India.

\subsection{Instrumentation}

In this paper, information pertaining to the analytical method validation and evaluation of combination drug has been provided. HPTLC is superior analytical technique in respect of the time and cost of analysis.

HPTLC technique comprises various independent offline stages. This includes application of samples on the precoated plate, scanning of the developed plates and densitogram etc. The most important features of this technique is to analyse the samples containing multi components in single analysis with the application of samples and standard solution on the same plate.

HPTLC Instrument possesses CAMAG automatic TLC sampler 4 (ATS4) connected with the win CATS 4 software , CAMAG TLC SCANNER, Integrator controlled by win CATS4 Software, CAMAG twin trough glass chamber with stainless steel lid.

In a $20 \times 10 \mathrm{~cm}$ twin trough glass chamber (Make: CAMAG), a linear ascending chromatographic development was carried out by using mobile phase, 1-Propanol: Methanol: Diethyl amine: Water in the ratio $(14: 2: 1: 2.5 \mathrm{v} / \mathrm{v})$. The chamber was saturated for 30 minutes. After development, TLC plate was dried in a current of hot air with the help of hair dryer. The plate was then dried on a CAMAG hot plate at $120^{\circ} \mathrm{C}$ for 2 minutes. A deuterium lamp was used in the UV range of 190 to $400 \mathrm{~nm}$ as a source of radiation. A slit dimension was $6.00 \times 0.45 \mathrm{~mm}$, micro, scanning speed was $20 \mathrm{mms}^{-1}$ and data resolution at $100 \mu \mathrm{m} / \mathrm{step}$. Sample was spotted on the silica gel $60 \mathrm{~F}_{254}$ TLC plate by using CAMAG automatic TLC sampler-4 (ATS). The plates were developed in the CAMAG TLC chamber upto $80 \mathrm{~mm}$. The contents of Ceftriaxone sodium and Tazobactam sodium were evaluated by comparing the peak areas with linear regression.

\section{Standard Solution Preparation}

$10 \mathrm{mg}$ of Ceftriaxone sodium and $10 \mathrm{mg}$ of Tazobactam sodium standards were accurately weighed and transferred to two separate $10 \mathrm{~mL}$ volumetric flasks. $2 \mathrm{~mL}$ of Methanol was added and sonicated for 5 minutes to dissolve. Then diluted to $10 \mathrm{~mL}$ with methanol (Labeled as Stock solution I and stock solution II for Ceftriaxone sodium and Tazobactam sodium respectively). $1 \mathrm{ml}$ from stock solution I and $2 \mathrm{~mL}$ from stock solution II were pipetted out in two separate volumetric flasks and diluted to $10 \mathrm{~mL}$ with methanol to obtain the 
concentration of $0.1 \mathrm{mg} / \mathrm{mL}$ and $0.2 \mathrm{mg} / \mathrm{mL}$ of standard Ceftriaxone sodium and Tazobactam sodium respectively.

\section{Sample Solution Preparation}

Label claim of Ceftriaxone sodium and Tazobactam sodium in the combined dry powder injection in one unit is $1000 \mathrm{mg}$ and $125 \mathrm{mg}$ respectively. To determine the content, 10 vial units were individually weighed. An average weight was recorded. Dry powder from all vials was mixed together to make a pooled sample. 50 $\mathrm{mg}$ from pooled sample was weighed, dissolved in 10 of methanol, sonicated for 5 minutes and diluted to $50 \mathrm{ml}$ with methanol. Further $1 \mathrm{ml}$ solution pipetted out in separate $10 \mathrm{ml}$ volumetric flask and diluted upto the mark with methanol to obtain the concentration of $0.1 \mathrm{mg} / \mathrm{ml}$ and $0.0125 \mathrm{mg} / \mathrm{ml}$ of Ceftriaxone sodium and Tazobactam sodium ( in the ratio 8:1) respectively.

\subsection{Validation of analytical method}

\section{Results and Discussions}

An analytical method developed was validated for the validation parameters Specificity, linearity, accuracy, precision, LOD, LOQ and Robustness. Validation of developed method was done as per ICH guideline Q2 (R1).

\subsubsection{Specificity}

A specificity was determined by analyzing reference standards, samples, diluent and mobile phase being used. This is to verify the interference of mobile phase and diluents during analysis. There was no any interference of Mobile phase and diluent at the $R f$ values of Ceftriaxone sodium and Tazobactam sodium. The separated bands of Ceftriaxone sodium and Tazobactam sodium were confirmed by comparing $R f$ values. Also separated bands were confirmed by overlaying standard UV spectra of the Ceftriaxone sodium and Tazobactam sodium recorded at Peak start ( S) Peak apex(M) and peak end(E) of both the drugs . Rf values of Ceftriaxone sodium and Tazobactam sodium were 0.50 and 0.67 respectively.

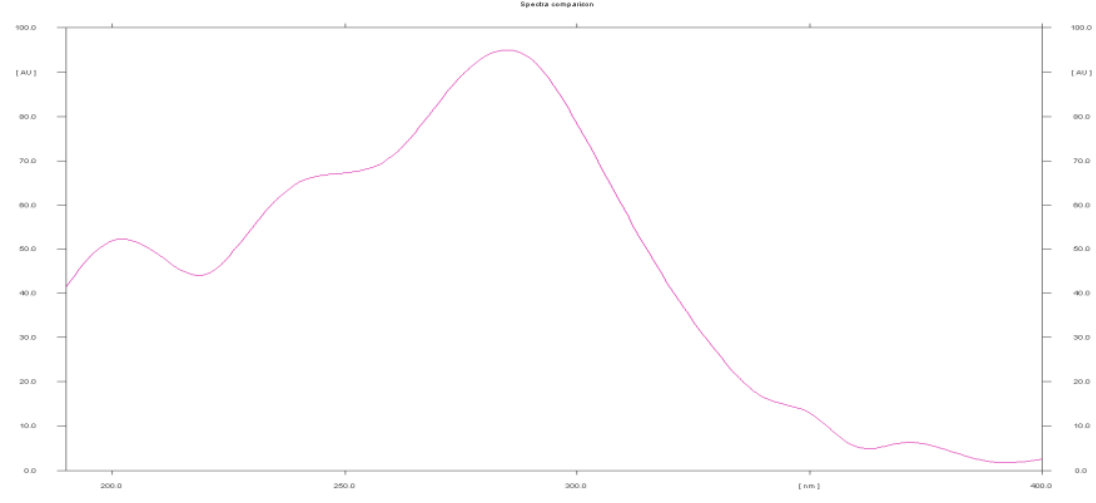

Figure 2: UV spectrum of Ceftriaxone sodium

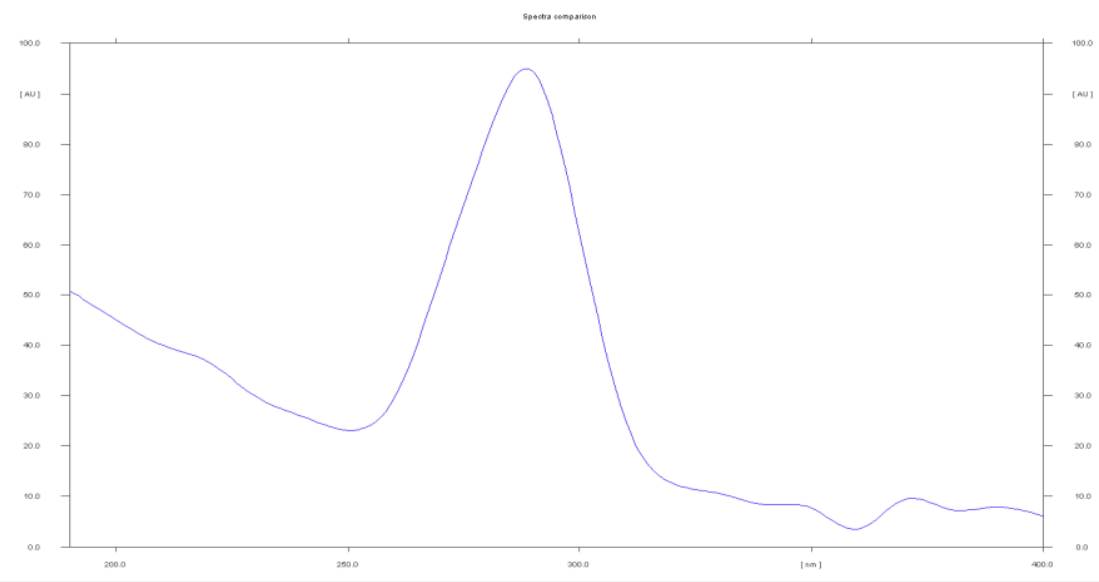

Figure 3: UV Spectrum of Tazobactam sodium 


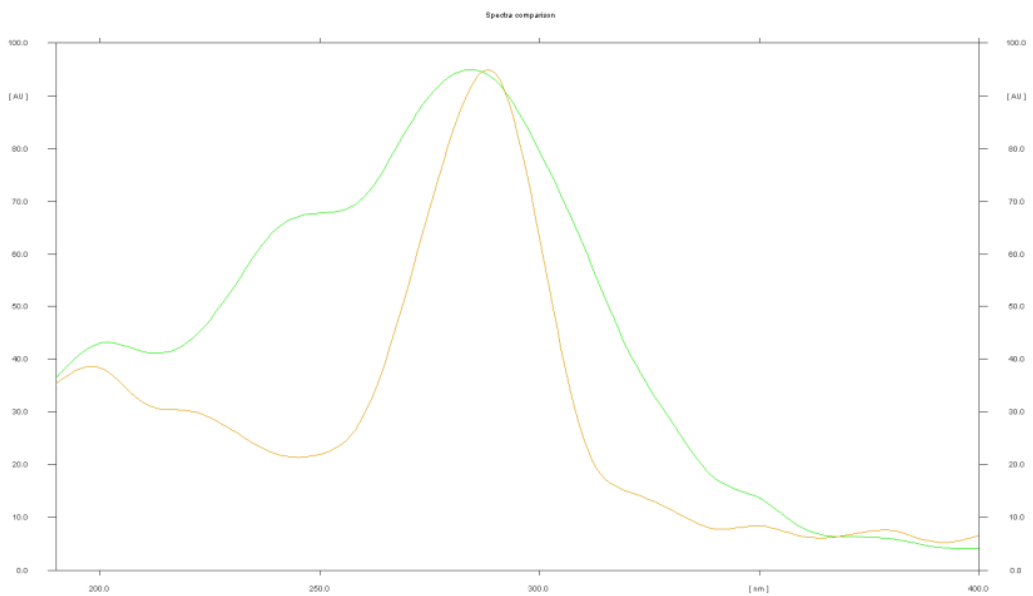

Figure 4: Overlain UV Spectra of Ceftriaxone sodium and Tazobactam sodium

\subsubsection{Accuracy}

In method validation, accuracy was determined by the percentage recovery.

The known concentrations of the samples were spiked with the standard Ceftriaxone sodium and Tazobactam sodium with the concentrations $40 \mathrm{ng}, 50 \mathrm{ng}$ and $60 \mathrm{ng}$ of Ceftriaxone sodium and $160 \mathrm{ng}, 200 \mathrm{ng}$ and $240 \mathrm{ng}$ of Tazobactam sodium respectively. The spiked samples were analysed by following the proposed analytical method. The percentage recovery of each spiked sample was calculated. The percentage recovery of Ceftriaxone sodium was in the range of $91.59 \%$ and $92.36 \%$ and for Tazobactam sodium , percentage recovery was $93.25 \%$ to $93.37 \%$. The detail recovery results are tabulated as under:

Table 1. : Percentage Recovery of Ceftriaxone sodium

$(\mathbf{n}=3)$

\begin{tabular}{|c|c|c|l|l|}
\hline $\begin{array}{c}\text { Sr. } \\
\text { No. }\end{array}$ & $\begin{array}{c}\text { Amount of std. Ceftriaxone } \\
\text { sodium added in ng }\end{array}$ & $\begin{array}{c}\text { Amount of std. Ceftriaxone } \\
\text { sodium recovered in ng }\end{array}$ & \% Recovery & $\begin{array}{c}\text { \% Relative } \\
\text { standard Deviation }\end{array}$ \\
\hline 1 & 40 & 36.94 & 92.36 & 0.32 \\
\hline 2 & 50 & 45.80 & 91.59 & 0.06 \\
\hline 3 & 60 & 55.06 & 91.77 & 0.09 \\
\hline
\end{tabular}

Table 2: Percentage Recovery of Tazobactam sodium

$(\mathbf{n}=3)$

\begin{tabular}{|c|l|l|l|l|}
\hline $\begin{array}{c}\text { Sr. } \\
\text { No. }\end{array}$ & $\begin{array}{c}\text { Amount of std. Tazobactam } \\
\text { sodium added in ng }\end{array}$ & $\begin{array}{c}\text { Amount of std. Tazobactam } \\
\text { sodium recovered in ng }\end{array}$ & \% Recovery & $\begin{array}{c}\text { \% Relative } \\
\text { standard Deviation }\end{array}$ \\
\hline 1 & 160 & 150.33 & 93.96 & 1.55 \\
\hline 2 & 200 & 186.74 & 93.37 & 0.20 \\
\hline 3 & 240 & 223.8 & 93.25 & 0.33 \\
\hline
\end{tabular}

\subsubsection{Precision}

The interday and intraday precision of the method were estimated by performing six determinations of Ceftriaxone sodium and Tazobactam sodium standard solutions. The analysis was carried by referring the developed method. Analytical results obtained are tabulated as under:

Table 3: Precision for the Ceftriaxone sodium

$(n=6)$

\begin{tabular}{|c|c|c|c|c|c|c|}
\hline \multirow{2}{*}{$\begin{array}{l}\text { Conc. of the } \\
\text { Ceftriaxone } \\
\text { sodium } \\
(\text { ng/ band })\end{array}$} & \multicolumn{3}{|c|}{ Inter-day precision } & \multicolumn{3}{|c|}{ Intra-day precision } \\
\hline & $\begin{array}{c}\text { Mean area } \\
(\mathbf{A U})\end{array}$ & SD & $\%$ RSD & Mean area $(\mathbf{A U})$ & SD & $\begin{array}{c}\% \\
\text { RSD }\end{array}$ \\
\hline 200 & 3403 & 49.7162 & 1.46 & 3405 & 49.2612 & 1.45 \\
\hline
\end{tabular}

Table 4: Precision for the Tazobactam sodium

$$
(\mathbf{n}=6)
$$

\begin{tabular}{|c|c|c|c|c|c|c|}
\hline \multirow{2}{*}{$\begin{array}{c}\text { Conc. of the } \\
\text { Tazobactam sodium } \\
\text { (ng/ band) }\end{array}$} & \multicolumn{3}{|c|}{ Inter-day precision } & \multicolumn{3}{c|}{ Intra-day precision } \\
\cline { 2 - 7 } & $\begin{array}{c}\text { Mean area } \\
\text { (AU) }\end{array}$ & SD & \% RSD & Mean area (AU) & SD \\
\hline 800 & 7342 & 101.6686 & 1.38 & 4853 & 101.1494 & 2.0 \\
\hline
\end{tabular}




\subsubsection{Robustness of the method}

A small deliberate change in the mobile phase composition was done and effect on the results was examined. Each component of the mobile phase with $\pm 0.1 \mathrm{~mL}$ of volume was varied and chromatogram was run. Also the small change in the volume of mobile phase was done and chromatogram was run $( \pm 5 \%$ of $20 \mathrm{~mL}$ )

The robustness of the method was determined at three different concentration levels. The results are tabulated as under:

Table 5: Robustness testing

\begin{tabular}{|l|c|c|c|c|c|c|}
\hline \multicolumn{1}{|c|}{ Parameter } & $\begin{array}{c}\text { Conc. Level in } \\
\text { ng/ band of } \\
\text { Ceftriaxone } \\
\text { sodium }\end{array}$ & $\begin{array}{l}\text { SD of Peak } \\
\text { response of } \\
\text { Ceftriaxone } \\
\text { sodium }\end{array}$ & \%RSD & $\begin{array}{c}\text { Conc. Level in ng } \\
\text { / band of } \\
\text { Tazobactam } \\
\text { sodium }\end{array}$ & $\begin{array}{c}\text { Mean Peak } \\
\text { response } \\
\text { Tazobactam } \\
\text { sodium }\end{array}$ & \%RSD \\
\hline $\begin{array}{l}\text { Mobile phase composition } \\
\text { (1-propanol: methanol: }\end{array}$ & 150 & 38.0208 & 1.40 & 300 & 14.012 & 1.30 \\
\cline { 2 - 8 } $\begin{array}{l}\text { DEA: water }) \\
(14.1: 2.1: 1.1: 2.6 \mathrm{v} / \mathrm{v})\end{array}$ & 250 & 6.6583 & 0.16 & 420 & 20.664 & 1.24 \\
\hline $\begin{array}{l}\text { Analysis by using 19 ml } \\
\text { mobile phase } \\
( \pm 5 \% \text { variation in mobile } \\
\text { phase volume) }\end{array}$ & 150 & 42.90 & 0.27 & 480 & 5.29 & 0.29 \\
\cline { 2 - 8 } & 200 & 42.724 & 0.92 & 300 & 45.797 & 1.81 \\
\cline { 2 - 8 } & 250 & 63.571 & 1.09 & 420 & 60.178 & 1.69 \\
\hline
\end{tabular}

\subsubsection{Linearity}

A series of standard solutions were prepared from the standard stock solutions of Ceftriaxone sodium and Tazobactam sodium. Solutions were spotted on the TLC plate in the range of $0.4 \mu 1$ to $2.0 \mu 1$ of Ceftriaxone sodium and $0.2 \mu 1$ to $1.8 \mu$ l of Tazobactam sodium respectively. The calibration curves were constructed by plotting

peak areas versus concentrations with the help of win-CATS software. The method is linear over the range of $100 \mathrm{ng}$ to $200 \mathrm{ng}$ for Ceftriaxone sodium and $160 \mathrm{ng}$ to $360 \mathrm{ng}$ for Tazobactam sodium. The regression coefficients for calibration curve of Ceftriaxone sodium and Tazobactam sodium were 0.9948 and 0 . 9992 respectively. The details are as under .

Table 6 : Regression analysis of the calibration curves for Ceftriaxone sodium and Tazobactam sodium

\begin{tabular}{|l|l|l|l|}
\hline Sr. No. & \multicolumn{1}{|c|}{ Parameters } & Ceftriaxone Sodium & Tazobactam Sodium \\
\hline 1 & Linearity Range & $100 \mathrm{ng}$ to $200 \mathrm{ng}$ & $160 \mathrm{ng}$ to $360 \mathrm{ng}$ \\
\hline 2 & Standard Deviation & 1.94 & 1.21 \\
\hline 3 & Slope & 12.91 & 10.78 \\
\hline 4 & Intercept & 68.2 & 583.9 \\
\hline 5 & Regression Coefficient & 0.9948 & 0.9992 \\
\hline 6 & Re-gression Equation & $12.91 \mathrm{X}+68.2$ & $10.78 \mathrm{X}+583.9$ \\
\hline 7 & LOD & $0.4959 \mathrm{mcg}$ & $0.3704 \mathrm{mcg}$ \\
\hline 8 & LOQ & $1.5027 \mathrm{mcg}$ & $1.1224 \mathrm{mcg}$ \\
\hline
\end{tabular}

\subsubsection{LOD and LOQ}

The Limit of Detection (LOD) and Limit of Quantitation (LOQ) were calculated from slope of the calibration curve. ICH guideline was referred for the formulae of Limit of Detection and Limit of Quantitation. $\mathrm{LOD}=3.3 \times(\sigma) / \mathrm{S}$ and $\mathrm{LOQ}=10 \times(\sigma) / \mathrm{S}$. Where, $\sigma=$ Standard deviation of the response and $\mathrm{S}=$ Slope of the calibration curve. LOD and LOQ for Ceftriaxone sodium are LOD= $0.4929 \mathrm{mcg}, \mathrm{LOQ}=1.5027 \mathrm{mcg}$, and for Tazobactam sodium $\mathrm{LOD}=0.3704 \mathrm{mcg}$ and $\mathrm{LOQ}=1.1224 \mathrm{mcg}$ respectively.

\subsubsection{Analysis of formulation}

Experimental HPTLC results of the amount of Ceftriaxone sodium and Tazobactam sodium in the dry powder Injectables were in good agreement with the label claim. The label claim of the marketed samples for Ceftriaxone sodium and Tazobactam sodium are $1000 \mathrm{mg}$ and $125 \mathrm{mg}$ per unit.

The drug content in the unit was found to be $98.8 \%$ and $101.5 \%$ for Ceftriaxone sodium and Tazobactam sodium respectively. 


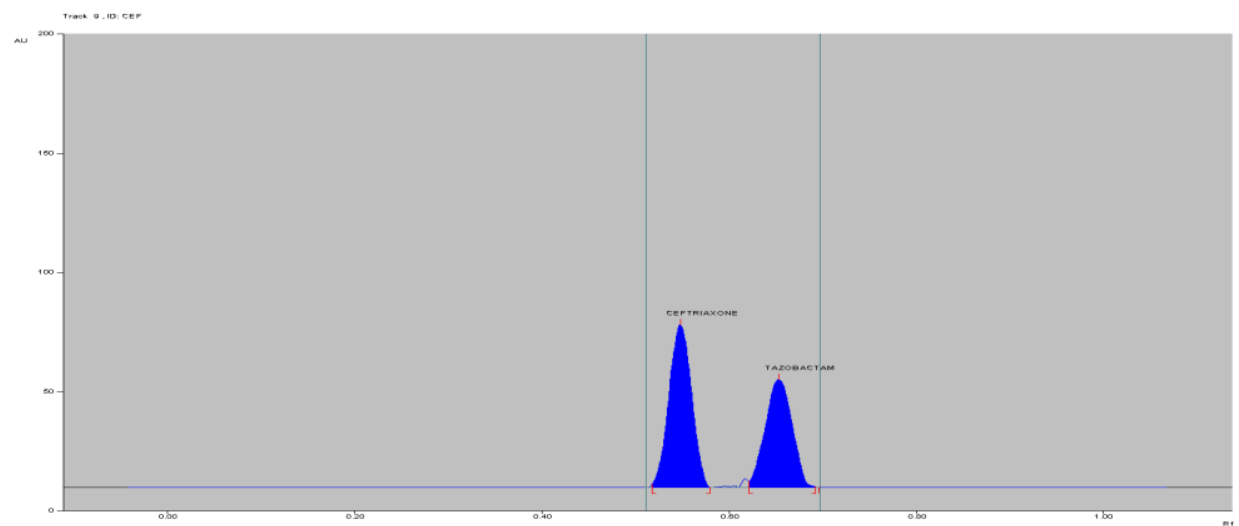

Figure 5: Densitogram of Ceftriaxone sodium $\left(\boldsymbol{R}_{f=0.50)}\right.$ and Tazobactam sodium $\left(\boldsymbol{R}_{f=0.67}\right)$

\section{Conclusion}

HPTLC analysis is rapidly becoming popular in routine analysis. This is due to its advantage of low operating costs, fresh stationary phase at every analysis and high sample throughput. This method can be used for simultaneous determination of Ceftriaxone sodium and Tazobactam sodium in routine analysis.

It may be extended to the degradation study of the Ceftriaxone sodium and Tazobactam sodium and also for its estimation in plasma and other biological fluids.

The proposed HPTLC method is simple, accurate, economically chief and reproducible.

\section{Acknowledgements}

The Authors wish to express many thanks to Mr. Vikrant Tamse-Senior purchase Manager for providing the reference standards required for the research work. We also thankful to Mr. Shahrukh BharuchaSenior Laboratory Manager -M/s Anchrom Testlab Pvt. Ltd. Mulund ( E) ,Mumbai-400081 for providing their support to carry an Analytical work at their well established Laboratory.

\section{References}

[1]. Bradley JS, Wassel RT, Lee L, Nambiar S (April 2009). "Intravenous ceftriaxone and calcium in the neonate: assessing the risk for cardiopulmonary adverse events". Pediatrics 123 (4):

[2]. R.Narendra Kumar, G.Nageswara Rao,P.Y.naidu, Stability indicating fast LC method for determination of ceftriaxone and tazobactam for injection related substances in bulk and pharmaceutical formulation. IJABPT, 2010, Volume: I: Issue-1 May-July.

[3]. Senem Sanli, Nurullah Sanli,et al. Simultaneous Estimation of Ceftazidime and Ceftizoxime in Pharmaceutical Formulations by HPLC Method,chromatographia, 2011 ,Volume 74, 7-8

[4]. Moreno Ade H, Salgado HR., Development of a new high-performance liquid chromatographic method for the determination of ceftazidime. PubMed, JAOAC Int., 2008, Jul-Aug,91(4); 739-43

[5]. Shaikh K.A.et. al., Method development and validation for third generation cephalosporin by uv-vis-spectrophotometer, IRJP, 2011, $2(1), 222-229$.

[6]. R.K.Nanda et.al., Development And Validation Of HPTLC Method For The Simultaneous Estimation Of Ceftazidime Sodium And Tazobactam Sodium In Marketed Formulatio, International Journal of Chem Tech Research CODEN( USA): IJCRGG ISSN : 0974-4290 Vol.4, No.4, pp 1701-1707, Oct-Dec 2012

[7]. Budavari S, editor. The Merck index. 13th. Whitehouse Station. NJ: Merck \& Co; 2001. p. 335.

[8]. The United States Pharmacopoeia, $36^{\text {th }}$ Revision. Rockville, MD: U.S. Pharmacopoeial Convention, Inc; 2013.

[9]. British Pharmacopoeia. II. London: Her Majesty's Stationary Office; 2007. p. 1965.

[10]. Zhao W, Zhang Y, Li Q. Indirect spectrophotometric determination of sodium ceftriaxone with n-propyl alcohol-ammonium sulfate-water system by extraction floatation of copper(II) Clin. Chim. Acta.2008;391:80-848.

[11]. Granich GG, Krogstad DJ. Ion pair high-performance liquid chromatographic assay for ceftriaxone. Antimicrob. Agents Chemother. 1987; 31:385-388.

[12]. Al-Momani IF. Spectrophotometric determination of selected cephalosporins in drug formulation using flow injection analysis. J. Pharm. Biomed. Anal. 2001; 25:751-757.

[13]. Sanjay Mohan shrivastava, Rajkumar singh, and Abu Tariq, A novel HPLC method for simultaneous determination of Ceftriaxone and sulbactam in sulbacomax., Internationl journal of biomedical sciences. 2009, Volume 5, 10-15.

[14]. Haginaka, J., H. Yasuda, T. Uno and T. Nkagawa, (1984). Alkaline degradation and determination by High-performance by highperformance liquid chromatography. Chem. Pharm. Bull., 32: 2752-2758

[15]. Higuchi, T., Brochman - Hansen, E., Edt. Pharmaceutical Analysis, Interscience, London, 1961Microbiol Lett.Mar 1;148(1):59-62. 